\title{
Importance of Performing Radiotherapy and Chemotherapy in the Same Clinic and Bad Prognostic Factors for Small-cell Lung Cancer Patients
}

\author{
Huriye Senay KIZILTAN'¹, Didem TASTEKIN², Ali Hikmet ERIS', Ozgur TASPINAR², Medina ISMAYLOVA' \\ Alpaslan MAYADAGLI ${ }^{1}$ \\ 'Department of Radiation Oncology, Bezmialem Vakıf University School of Medicine, İstanbul, Turkey \\ ${ }^{2}$ Department of Medical Oncology, Bezmialem Vakıf University School of Medicine, İstanbul, Turkey \\ ${ }^{3}$ Department Physical Medicine and Rehabilitation, Bezmialem Vakıf University School of Medicine, İstanbul, Turkey
}

\section{ABSTRACT}

Objective: We evaluated different treatment results reported and showed the effect of treatment at single and multiple clinics for smallcell lung cancer (SCLC). We attempted to show a decreasing impact of chemotherapy (CT) and thoracic radiotherapy (RT) treatment results when implemented at different clinics for SCLC compared to the treatment results at a clinic.

Methods: We conducted a retrospective study on 54 non-metastatic SCLC patients who underwent treatments at various clinics. Patients underwent 1-12 courses of CT before they came to the clinic for thoracic RT. RT was performed at 180-400 cGy dose per fraction for a total of 30-52 Gy doses, and patients were followed for 12-60 months.

Results: When the study was reviewed, the results showed that the median disease-free survival and survival rates were 8 and 9 months and that the 2-, 5-, and 5-year survival rates were $8 \%, 6.3 \%$, and $1.8 \%$, respectively. The median progression-free survival rates for 2 and 3 years were $4 \%$, and for 5 years, it was $1.8 \%$. Weight loss for disease-free survival $(\mathrm{p}=0.01)$ and superior vena cava syndrome for overall survival $(\mathrm{p}=0.02)$ were considered as bad prognostic factors. In this study, acceptable toxicity values were found when the results were compared with those from other studies.

Conclusion: We obtained worse results than those from literature data on our SCLC patients who came to our clinic after the progression of their disease. The main causes were identified as insufficient staging and different treatment protocols applied at different clinics. Therefore, we argue that CT and thoracic RT for SCLC must be performed at the same clinic and that the same protocols and staging methods must be used.

Keywords: Small cell lung cancer, chemoradiotherapy, vena cava syndrome

\section{Introduction}

Small-cell lung cancer (SCLC) is an aggressive form of lung cancer. Its unique pathological and clinical features were first recognized by Barnard (1). There is a tendency for early dissemination. It has high initial response rates to chemotherapy (CT). An autopsy series on small cell carcinoma patients showed a high frequency of metastases because more than $95 \%$ of patients die from the cancer (2).

The tumor node metastasis staging system is not used because surgical resection is generally not possible. Therefore, the Veterans Administration Lung Study Group system is used as the staging system (3).

A vast majority of patients are symptomatic at presentation. In most cases, they are diagnosed by bronchoscopic biopsy, and usually, additional tissues for immunohistochemical staining are required. Limited-stage disease should be treated with CT concurrently with early thoracic radiotherapy (RT). Prophylactic cranial RT should be considered for all patients to achieve complete remission. Extensive-stage disease should be treated by combination CT administered for 4-6 cycles $(4,5)$. 
In total, $60-70 \%$ of patients present with extensive-stage disease. These patients have a median survival and 5-year survival rate of $7-12$ and $2 \%$, respectively. However, for limited-stage disease, the median survival is approximately 23 months and the 5-year survival rate is $12-17 \%$ (6).

Metastases in the central nervous system have been identified in $80-90 \%$ of patients $(7,8)$.

Favorable prognostic factors in SCLC patients are a good performance status, limited-stage disease, female sex, and normal serum lactate dehydrogenase levels. Inconsistently reported prognostic factors are few sites of metastatic disease, age $<40$ years, absence of pleural effusion, brain metastases, liver metastases, and normal serum sodium and liver function tests (9).

In general, etoposide-cisplatin together with thoracic RT is used for the limited-stage disease. This treatment results in a complete response rate of $80 \%$ or higher, a median survival in excess of 17 months, and a 5-year cancer-free survival rate of $12-25 \%$ in best series $(6,4,10,5)$.

Topotecan was superior to CAV for providing relief from general symptoms, including anorexia, fatigue, dyspnea, and hoarseness (11). Topotecan is also superior for relapsed SCLC (12).

Hematologic toxicity, cisplatin-induced nephrotoxicity, and paclitaxel-induced neurotoxicity are common toxicities associated with treatment for SCLC. Generally, patients show greater improvements in the quality of life, despite intensive regimens during the first four course of CT. The quality of life declines very quickly when CT is extended to more than four courses (13). Furthermore, survival advantages were not obtained by extending the treatment to beyond $4-6$ courses $(14,15)$.

Many SCLC and lung cancer patients were elderly and had relapsing disease or multiple comorbidities. Therefore, they were unable to tolerate intensive CTs. Many oncologists have also been reluctant to re-treat these relapsing elderly and badly performing patients. Symptom palliation and the quality of life are more important factors in the design of treatment rather than prolonging the survival $(16,17)$. Single-agent oral or intravenous CT or supportive care may be the best option for elderly or poorly performing patients (18).

Treatment for SCLC is often performed in different protocols in different clinics. Different treatment results have been reported in many studies on SCLC. There are various causes for these outcomes. CT is usually performed with distinct course numbers and regimens at different clinics. Further, thoracic RT is performed with various doses and fractionation schedules. Nowadays, the RT volume is controversial (19). We attempted to show a decreasing impact on treatment results of CT and RT when performed at different clinics for treating

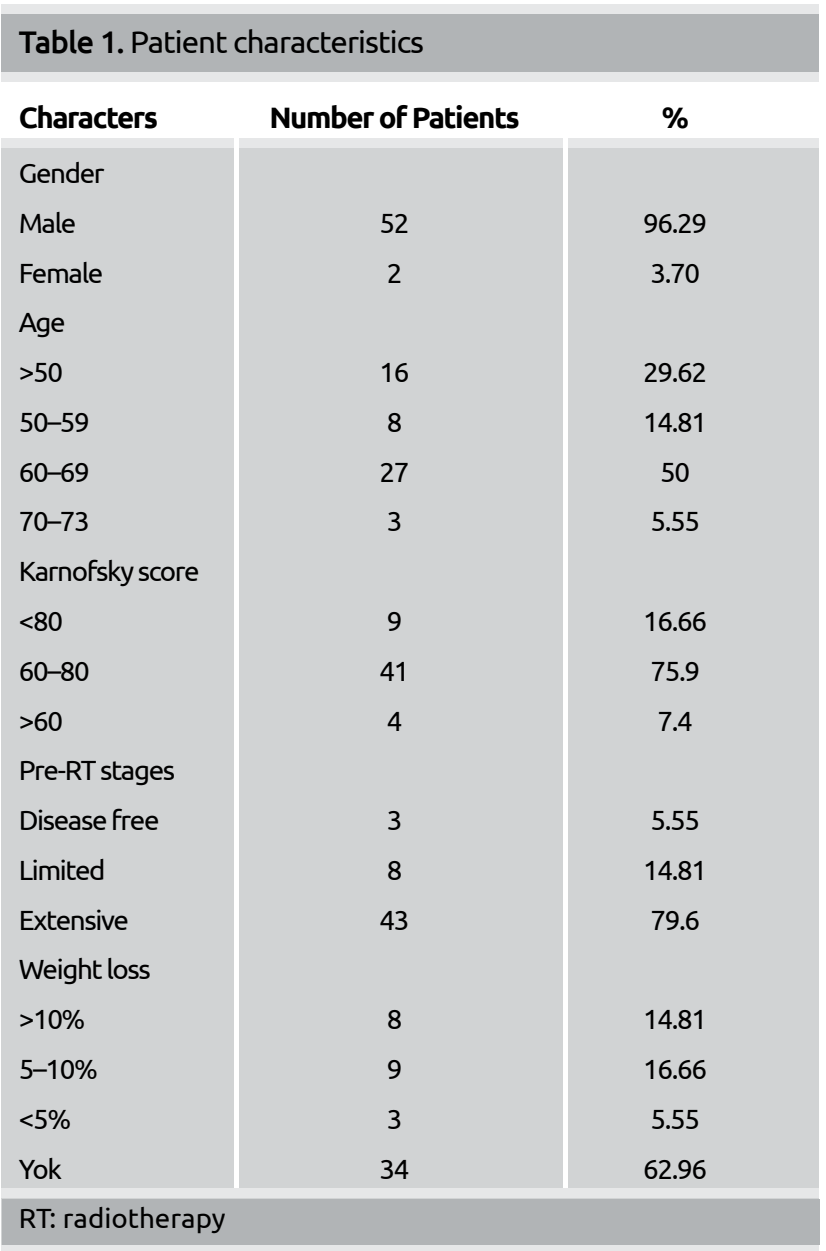

\section{Methods}

We conducted a retrospective study on 54 non-metastatic SCLC patients whose treatments were performed in various clinics between 1980 and 1993. One to twelve course of CT were performed before the patients came to the clinic for thoracic RT. RT was performed at 180-400 cGy dose per fraction for a total of 30-52 Gy doses, and they were followed for 12-60 months. The Veterans Administration Lung Study Group staging system was used as the staging method. Pre-CT stage information of patients and pre-RT stages were confirmed. Forty-three patients had limited-stage disease according to the pre-RT evidence. Patient characteristics are shown in Table 1.

CT was performed for at least 1 and up to 12 courses at the time of pre-RT. The CT regimens are shown in Table 2.

Thoracic RT was performed at a median dose of $250 \mathrm{cGy} /$ day and at least $180 \mathrm{cGy} /$ day, up to $400 \mathrm{cGy} /$ day fraction dose for 5 consecutive days a week. LINAC-based therapy was used for 25 patients, whereas others were treated with cobalt-60 teletherapy unit. RT planning was obtained according to pre-RT lung tumor volumes in all patients. Planning was used as $1-\mathrm{cm}$ margin to tumor and additional nodes at risk (Table 3 ). 
Table 2. Chemotherapy regimens before radiotherapy and response rates

\begin{tabular}{|c|c|c|c|c|c|c|}
\hline CT Regimens & Number of patients & Complete responders & Partial responders & Minimal responders & Stationer & Progressive \\
\hline$P$ & 16 & 1 & 4 & 1 & 8 & 2 \\
\hline A & 12 & 0 & 2 & 1 & 7 & 2 \\
\hline $\mathrm{P}+\mathrm{A}$ & 46 & 0 & 3 & 0 & 1 & 0 \\
\hline Others & 6 & 0 & 1 & 0 & 2 & 3 \\
\hline Not known & 16 & 2 & 4 & 3 & 6 & 1 \\
\hline Total & 54 & 3 & 14 & 5 & 24 & 8 \\
\hline
\end{tabular}

\begin{tabular}{|c|c|c|}
\hline Radiotherapy & Number of patients & $\%$ \\
\hline \multicolumn{3}{|l|}{ Total dose (Gy) } \\
\hline$>44$ & 22 & 40.74 \\
\hline$\leq 44$ & 32 & 59.25 \\
\hline \multicolumn{3}{|l|}{ Volume } \\
\hline P+M+BilatS & 14 & 25.92 \\
\hline $\mathrm{P}+\mathrm{M}+\mathrm{S}$ & 20 & 17.03 \\
\hline$P+M$ & 19 & 35.19 \\
\hline P+M+Aksilla & 1 & 1.85 \\
\hline
\end{tabular}

Table 4. Response rates of patients at first treatments as pre-RT (outclinic treatment responses)

\begin{tabular}{|l|c|c|}
\hline Pre-RT responses & Number of patients & $\%$ \\
\hline CR & 3 & 5.55 \\
PR & 14 & 25.02 \\
MR & 5 & 9.25 \\
Stationer & 24 & 44.4 \\
Progression & 8 & 14.8 \\
\hline RT: radiotherapy; CR: complete response; PR: partial response; \\
MR: minimal response
\end{tabular}

Pre-RT staging was performed, and the response rates of primary treatment are shown in Table 4.

\section{Statistical analysis}

Survival analysis was performed using the Kaplan-Meier method. The ratios between the groups were analyzed by the qi-square test.

\section{Results}

Weight loss was shown to be the most prominent bad prognostic factor for disease-free survival $(\mathrm{p}=0.01)$ and superior vena cava syndrome or overall survival $(p=0.02)$, which were assessed with the chi-square test (nonparametric statistic test,

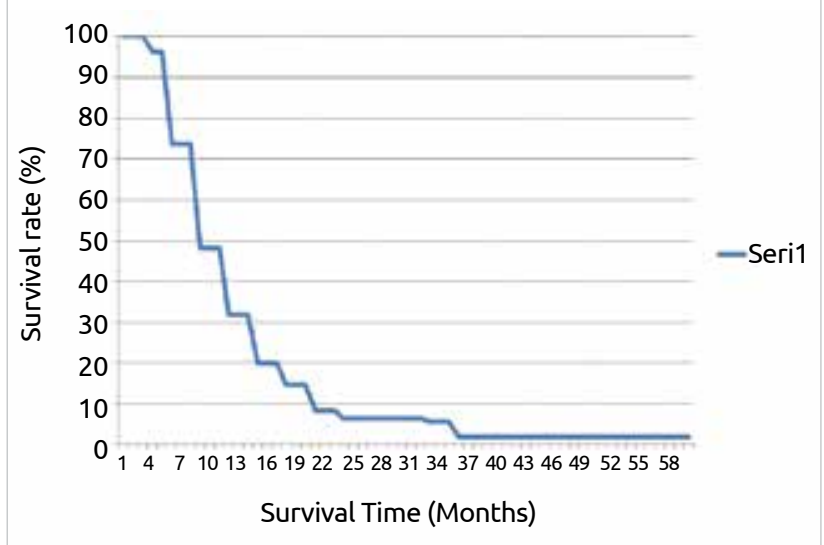

Figure 1. Survival curve for SCLC in this study

İn USA, 1934). No factor was determined for local control except the CT and RT responses.

The median survival was 9 months, and the 2-, 3-, and the 5 -year survival rates were $8 \%, 6.3 \%$, and $1.8 \%$, respectively, which were assessed by the Kaplan-Meier method ("Nonparametric estimation from incomplete observations", in USA, 1958).

As shown in Figure 1, the median disease-free survival rate was 9 months, and the 2-, 3-, and 5-year disease-free survival rates were $4 \%, 4 \%$, and $1.8 \%$, respectively. The complete response rate increased to $20.37 \%$ post RT, while it was $5.55 \%$ pre RT. The partial response rate increased to $53.7 \%$ post RT, while it was $25.92 \%$ pre RT.

The grade I eusophagit was $66.6 \%$, grade II was $14.8 \%$, and grade III was $3.6 \%$. Grade I hematologic toxicity was $66.6 \%$, grade II was $27.7 \%$, and grade III was $14.8 \%$. The grade I radiation pneumonia was shown $27.7 \%$, grade II was $14.8 \%$, and grade III was 3.6\%.

\section{Discussion}

SCLC accounts for approximately $18 \%$ of the lung cancers (20). The 5-year survival rates with limited ranges from 5\% to $10 \%$. In total, $60-70 \%$ of patients present extensive-stage disease. These patients have a median survival and 5-year sur- 
vival rate of $7-12$ and $2 \%$, respectively. The median survival for extensive-stage SCLC patients is approximately 8 months $(21,22,23)$. However, in the limited-stage disease, the median survival is approximately 14-23 months and the 5-year survival rate is $12-17 \%(4,5,6,15)$.

A bad performance status, number and location of metastases, disease-free interval, and unsuccessful first-line CT are very important bad prognostic factors. Survival was clearly improved in patients who responded to first-line treatment. The progression-free interval was under 3 months following first-line treatment for chemoresistant patients. The median survival is generally comparable or slightly superior to the best supportive care cases (i.e., 16-21 weeks) $(24,25)$. The prognosis is generally unfavorable in relapsed patients, with an unsatisfactory proportion of patients surviving for more than 1 year.

The median survival was 8-9 months in relapsed SCLC associated with currently existing therapies (26).

The survival of recurring and/or progressive advanced SCLC is 1.5-4 months for the best supportive care. There have been no large randomized trials to compare the survival among patients who had CT compared with those who had the best supportive care. The largest randomized study conducted to date for relapsed SCLC patients shows that the survival could be significantly improved for patients receiving short-term treatment ( 4 courses) compared with those receiving symptomatic treatment (median survival: 20 vs. 11 weeks, respectively; $\mathrm{p}<0.001)(27)$. Other studies on active intervention with CT in relapsed patients have reported median survivals ranging from 6 to 8 months $(28,29,11,24,25)$.

In SCLC, most patients relapse and have a poor prognosis. Treatment options include RT, CT, or combined modalities for relapsed patients. Potential barriers to further treatment include toxicity, patient comorbidities, and performance status. However, numerous clinical trials have demonstrated that some patients benefit from different treatment regimens (30).

The complete response rate increased to $20.37 \%$ post RT, while it was $5.55 \%$ pre RT in this study. The partial response rate increased to $53.7 \%$ post RT, while it was $25.92 \%$ pre RT. These results suggest that RT is effective for the patients who do not shown a good response to CT despite the different reported results in the literature $(5,31)$. The response rates to CT for SCLC were $60-95 \%$ in many studies $(6,4,10$, $5)$. However, the total response rate to CT was $45 \%$ in our study because these patients were sent from other clinics after disease progression or bad results of CT.

In this study, acceptable toxicity values were found when the results were compared with those from other studies $(10,13)$.

The CT responses are very significant during the first 6 weeks of treatment (19). The clinical tendency to send patients who do not show a good response to different clinics is a very important factor that reduces the effectiveness of treatments. Because of the lack of good communication among doctors, other staff and the patient, valuable time is lost when patient transfer takes place. Some clinics may not readily accept patients whose treatment might have started at other clinics. After the transfer, required diagnostic tests may not be performed to not disturb the patient response and to control the overall treatment cost. As a result, the actual staging may not be properly updated and the treatment history applied at other clinics may not be understood.

When the study reviewed, the results showed that the median disease-free survival and survival were 8 and 9 months and that the 2-, 3-, and 5-year survival rates were $8 \%, 6.3 \%$, and $1.8 \%$, respectively. The $2-, 3$-, and 5-year progression-free survival rates were $4 \%, 4 \%$, and $1.8 \%$, respectively. Weight loss for disease-free survival $(\mathrm{p}=0.01)$ and superior vena cava syndrome for overall survival $(\mathrm{p}=0.02)$ were considered as bad prognostic factors.

The wrong staging, different treatment protocols, and disease progression contributed to the relatively negative treatment results of patients sent from other clinics for various reasons according to other studies. Therefore, we argue that CT and RT for SCLC must be performed in the same clinic that uses the same protocols and staging methods.

Ethics Committee Approval: Ethics committee approval was not received due to the retrospective nature of this study.

Informed Consent: Written informed consent was not received due to the retrospective nature of this study.

Peer-review: Externally peer-reviewed.

Author Contributions: Concept - H.Ş.K.; Design - H.Ş.K., D.T.; Supervision - A.M., A.H.E.; Data Collection and/or Processing - H.Ş.K., D.T.; Analysis and/or Interpretation - Ö.T.; Literature Review - H.Ş.K., D.T.; Writing - H.Ş.K.; Critical Review - M.İ., A.M.

Acknowledgement: We are pleased to Güven Yücesan for his edition.

Conflict of Interest: No conflict of interest was declared by the authors.

Financial Disclosure: The authors declared that this study has received no financial support.

\section{References}

1. Barnard W. The nature of the 'oat-celled sarcoma' of the mediastinum. J Pathol 1926; 29: 241-4. [CrossRef]

2. Watson WL, Berg JW. Oat cell lung cancer. Cancer 1962; 15: 759-68. [CrossRef]

3. Zelen M. Keynote address on biostatistics and data retrieval. Cancer Chemother Rep 1973 ; 3: 31-42.

4. David MJ, Bruce EJ. Small-cell lung cancer. Seminar 2005; 366: 1385-96.

5. Bayman E, Etiz D, Akcay M, Ak G. Timing of thoracic radiotherapy in limited stage small cell lung cancer: results of early versus late irradiation from a single institution in Turkey. Asian Pac J Cancer Prev 2014; 15: 6263-7. [CrossRef] 
6. Janne PA, Freidlin B, Saxman S, et al. Twenty-five years of clinical research for patients with limited-stage small cell lung carcinoma in North America. Cancer 2002; 95: 1528-38. [CrossRef]

7. Hochstenbag MM, Twijnstra A, Wilmink JT, et al. Asymptomatic brain metastases (BM) in small cell lung cancer (SCLC): MR-imaging is useful at initial diagnosis. J Neurooncol 2000; 48: 243-48. [CrossRef]

8. Richardson GE, Venzon DJ, Edison M, et al. Application of an algorithm for staging small-cell lung cancer can save one third of the initial evaluation costs. Arch Intern Med 1993; 153: 329-37. [CrossRef]

9. Paesmans M, Sculier JP, Lecomte J, et al. Prognostic factors for patients with small cell lung carcinoma: analysis of a series of 763 patients included in 4 consecutive prospective trials with a minimum follow-up of 5 years. Cancer 2000; 89: 523-33. [CrossRef]

10. Zhang J, Qi HW, Zheng H, et al. Etoposide-cisplatin alternating with vinorelbine-cisplatin versus etoposide-cisplatin alone in patients with extensive disease combined with small cell lung cancer. Asian Pac J Cancer Prev. 2014; 15: 4159-63. [CrossRef]

11. Von PJ, Schiller JH, Shepherd FA, et al. Topotecan versus cyclophosphamide, doxorubicin, and vincristine for the treatment of recurrent small-cell lung cancer. J Clin Oncol 1999; 17: 658-67.

12. Altinbas M, Kalender ME, Oven B, et al. Weekly topotecan for recurrent small cell lung cancer - a retrospective Anatolian Medical Oncology Group study. Asian Pac J Cancer Prev 2012; 13: 2909-1. [CrossRef]

13. Wolf M, Pritsch M, Drings P, et al. Standard vs palliation chemotherapy in metastatic small cell lung cancer: An analysis on treatment efficacy and quality of life. Lung Cancer 1994; 11: S92. [CrossRef]

14. Bunn PA, Carney DN. Overview of chemotherapy for small cell lung cancer. Semin Oncol 1997; 24: 7-74.

15. Zochbauer-Muller S, Pirker R, Huber H. Treatment of small cell lung cancer patients. Ann Oncol 1999; 10: 83-91. [CrossRef]

16. Stephens RJ, Hopwood P, Girling DJ. Defining and analysing symptom palliation in cancer clinical trials: A deceptively difficult exercise. Br J Cancer 1999; 79: 538-44. [CrossRef]

17. Kiziltan HS, Bayir AG, Tastekin D, et al. Outcome of Daily Cisplatin with Thoracic Chemoradiotherapy in Advanced Non-small Cell Lung Cancer Patients with Comorbid Disorders: A Pilot Study. Asian Pac J Cancer Prev 2014; 15: 8591-4. [CrossRef]

18. Fields SZ, Eckardt JR, Zhang L, et al. Efficacy of reduced dose of IV topotecan (T) in relapsed small cell lung cancer (SCLC) patients (abstract 26). Lung Cancer 2000; 29(1):10. [CrossRef]

19. Salazar OM. Creech, State of the art toward defining the role of radiation therapy in the management of small cell bronchogenic carcinomaR.H. Int. J. Radiat. Oncol., Biol. Phys.1980; 6(8): 1103-1117. [CrossRef]
20. Ries LAG, Hankey BF, Miller BA, et al. SEER Cancer Statistics Review, 1973-1988. Bethesda, Md, National Institutes of Health.1991

21. Pujol JL, Daures JP, Riviere A, et al. Etoposide plus cisplatin with or without the combination of 4 '-epidoxorubicin plus cyclophosphamide in treatment of extensive smallcell lung cancer: A French Federation of Cancer Institutes multicenter phase III randomized study. J Natl Cancer Inst.2001; 93:300-308. [CrossRef]

22. Roth BJ, Johnson DH, Einhorn LH, et al. Randomized study of cyclophosphamide, doxorubicin, and vincristine versus etoposide and cisplatin versus alternation of these two regimens in extensive small-cell lung cancer: A phase III trial of the Southeastern Cancer Study Group. J Clin Oncol.1992; 10:282-291.

23. Urban T, Chastang C, Lebas FX, et al. The addition of cisplatin to cyclophosphamidedoxorubicin- etoposide combination chemotherapy in the treatment of patients with small cell lung carcinoma: A randomized study of 457 patients. "Petites Cellules" Group. Cancer.1999; 86:22382245. [CrossRef]

24. Depierre A, von Pawel J, Hans K, et al. Evaluation of topotecan (Hycamtin) in relapsed small cell lung cancer (SCLC). A multicenter phase II study. Lung Cancer.1997; 18(1):35. [CrossRef]

25. Eckardt J, Gralla R, Palmer MC, et al. Topotecan (T) as second-line therapy in patients (Pts) with small cell lung cancer (SCLC): A phase II study. Ann Oncol.1996;7(5):107.

26. Montazeri A, Gillis CR, McEwen J. Quality of life in patients with lung cancer: A review of literature from 1970 to 1995 . Chest.1998;113:467481. [CrossRef]

27. Spiro SG, Souhami RL, Geddes DM, et al. Duration of chemotherapy in small cell lung cancer: A Cancer Research Campaign trial. Br J Cancer.1989; 59: 578-583. [CrossRef]

28. Kosmidis PA, Samantas E, Fountzilas G, et al. Cisplatin/etoposide versus carboplatin/ etoposide chemotherapy and irradiation in small cell lung cancer: A randomized phase III study. Hellenic Cooperative Oncology Group for Lung Cancer Trials. Semin Oncol.1994; 21(6):23-30.

29. Girling DJ. Comparison of oral etoposide and standard intravenous multidrug chemotherapy for small-cell lung cancer: A stopped multicentre randomised trial. Medical Research Council Lung Cancer Working Party. Lancet. 1996; 348:563-566. [CrossRef]

30. John R. Eckardt, MD. Second-Line Treatment of Small-Cell Lung Cancer. Lung Cancer, Oncology Journal, Review Article.2003.

31. Nagy-Mignotte H, Guillem P, Vignoud L, et al. Multidisciplinary Thoracic Oncology Group. Outcomes in recurrent small-cell lung cancer after one to four chemotherapy lines: a retrospective study of $300 \mathrm{pa}-$ tients. Lung Cancer 2012; 78: 112-20. [CrossRef] 